\title{
Approach to the organization of decision support in the formulation of innovative regional development strategies based on adaptive-simulation model
}

\section{Lilia R. Chernyakhovskaya ${ }^{a}$}

E-mail: 1rchern@yandex.ru

\section{Marsel M. Nizamutdinov ${ }^{\mathrm{b}}$ (D)}

E-mail:marsel_n@mail.ru

\section{Vladimir V. Oreshnikov ${ }^{\mathrm{b}}$}

E-mail:VOresh@mail.ru

\section{Alsouy R. Atnabaeva ${ }^{\mathrm{b}}$}

E-mail: Alsouy@mail.ru

\author{
${ }^{a}$ Ufa State Aviation Technical University \\ Address: 12, Karl Marx Street, Ufa 450008, Russia \\ ${ }^{\mathrm{b}}$ Ufa Federal Research Center, Russian Academy of Sciences \\ Address: 71, Prospekt Oktyabrya, Ufa 450054, Russia
}

\begin{abstract}
This article deals with the formulation of a decision support system (DSS) in the field of regional development management. The review of existing approaches in this area presented here attests, on the one hand, to their diversity, and on the other hand allows us to draw conclusions about the need to address several methodological and practical issues of decision support in terms of innovative development of regions. Based on this, the goal of the research was to develop the concept of DSS to justify the parameters of an innovative development strategy for regional development based on adaptive mechanisms for coordinating the interests of economic agents.
\end{abstract}


The methodology of the study is based on the synthesis of various approaches in the framework of integration into the structure of adaptive simulation models of problem-oriented knowledge bases with the mechanism of logical inference, as well as intelligent technologies for processing semi-structured information used to find solutions in the process of shaping and adjusting the parameters for managing innovative development of a region. The result of the study is a theoretical justification for developing problem-oriented DSS, including a description of the interrelated stages that determine the main design features of this tool. In the framework of the study, a conceptual scheme for implementing DSS in the field of managing innovative development of regions is proposed, and the key functional blocks of the proposed tools are described. In addition, the place of existing tools in the structure of the regional development management system is determined, and we show the possibilities of their use in the formation of forecast-planned assessments of the development of the region, as well as in the evaluation of the effectiveness of alternative management actions. The proposed tools will expand the possibilities of applying the methods of management theory and decision support, intelligent information technology, economic and mathematical methods and modern computer simulation technologies for strategic planning of socio-economic systems of macro- and meso-level. In practice, the tools may be of interest to public authorities in solving problems in in the formulation of innovative regional development strategies for Russian regions, the formation of medium-term forecasts and the justification of the parameters of social, economic and budgetary policy.

\section{Graphical abstract}

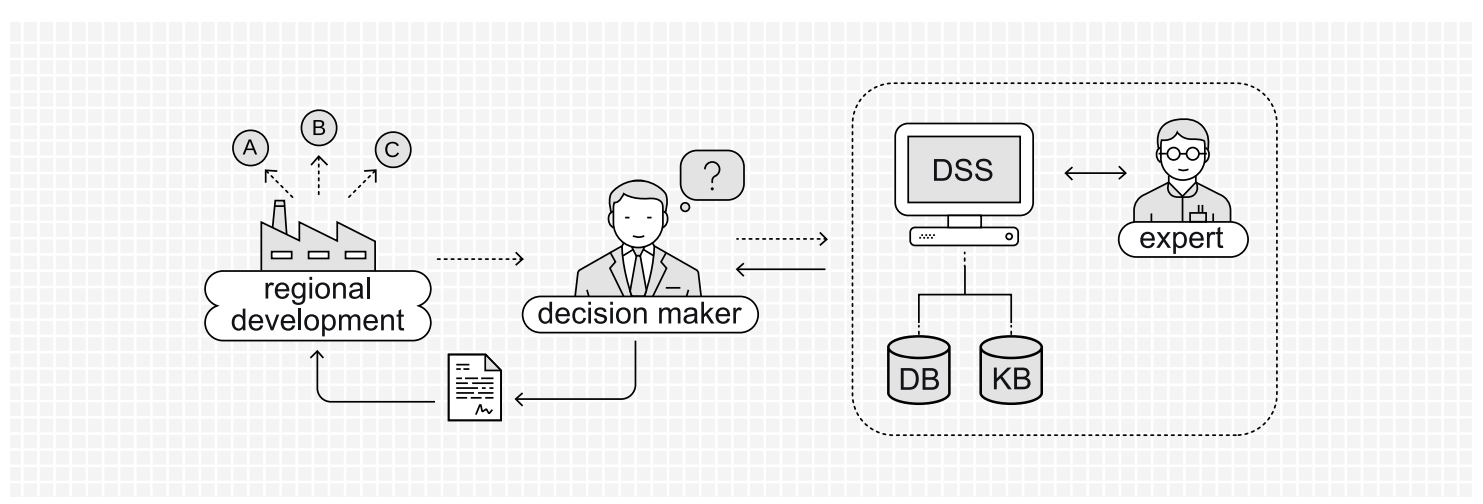

Key words: decision support; innovative development; simulation modeling; adaptive modeling; regional management; forecasting and planning.

Citation: Chernyakhovskaya L.R., Nizamutdinov M.M., Oreshnikov V.V., Atnabaeva A.R. (2019) Approach to the organization of decision support in the formulation of innovative regional development strategies based on adaptive-simulation model. Business Informatics, vol. 13, no 3, pp. 20-34.

DOI: $10.17323 / 1998-0663.2019 .3 .20 .34$ 


\section{Introduction}

$\mathrm{T}$ he regional socio-economic system by virtue of its nature is a complex, multiaspect and multi-purpose system, including many elements and heterogeneous relationships in all spheres of society. Ongoing economic processes have a direct influence on the stability and sustainability of the development of the region as a whole. Moreover, in the context of global competition for various types of limited resources, the determining factor is the ability of regional authorities to facilitate the innovative potential of the population and enterprises. The formulation of appropriate strategies for innovative development needs in-depth comprehensive substantiation, determination of target reference points, a resource base and optimal ways to solve the assigned tasks. In this regard, an objective condition for the formation of an effective economic policy is the widespread use of scientifically sound management tools, which, in particular, include the tools for developing and substantiating the parameters of innovative development of the region. At the same time, accelerated economic growth should not contradict the more global task of achieving balanced development of both the real sector of the economy and the social sector of the region.

Research in the field of formulating economic and mathematical models and tools for managing the strategic development of complex social and economic systems and, in particular, planning innovative development to one degree or another, has been carried out in recent decades in most developed countries of the world. Currently many software products have been developed that allow us to solve the set of problems of forecasting regional development [1]. However, the vast majority of modern Russian technologies are still based on the prerequisites for the functioning of a planned economy and do not reflect current market conditions for conducting business in the Russian Federation. Moreover, existing technolo- gies mainly reflect the inertial mechanisms of territorial development and are not aimed at solving urgent problems of ensuring accelerated economic growth based on the transition to an innovation-oriented development model.

Thus, there are objective prerequisites for improving the currently used simulation tools due to the wider use of simulation modeling, conducting scenario experiments, taking into account the objective possibilities and restrictions of the regions. In aggregate, this allows us to formulate specific mechanisms and set conditions for achieving socially significant development priorities.

\section{Review of existing approaches}

Analysis of the current state of research in the field of organizing decision support for the development of strategies promoting innovative development of the regions implies a comprehensive review of issues of strategic management, the theory of innovative economics and development of decision support systems (DSS). Separately, we should mention the issues of developing economic and mathematical models in relation to the problem under consideration.

These areas have a well-developed scientific base. In particular, the basic tenets of the theory of innovative economics were formed already by J. Schumpeter. A number of aspects are considered in studies of Kondratiev's long waves, diffusions of C. Freeman's innovations, and also the technological paradigm of S.Yu. Glazyev, C. Peres, D.S. Lvov, Yu.V. Yakovets et al. However, the majority of the available studies are not fully focused on quantitative assessment and forecast of the influence of factors of innovative development on the evolution of territorial social and economic systems.

In order to solve this problem, it seems necessary to use specialized tools, in particular, decision support systems (DSS) [2]. How- 
ever, unfortunately, within the framework of the problems being studied, most of the existing technologies are focused on the tasks of managing the development of individual enterprises or activities. However, at the regional level, where issues of developing strategies for innovative development are being addressed, these systems do not find practical application. Certain works in this area (information and analytical DSS on managing innovative activity in regions [3], DSS on strategy for innovative development of regions [4], etc.) only partially reflect such an essential property of the regional system as adaptability of behavior of key economic entities [5], or have exclusively theoretical or industry-specific significance [6].

Various directions have also developed in the field of economic and mathematical modeling of social and economic processes (general economic equilibrium models, simulation modeling, probabilistic-statistical models, etc.). At the same time, the models used in practice are mainly mixed and combine the features of several different approaches [7]. The most famous foreign models in this area are the Wharton annual model of the US economy, the LIFT model, the Brookings model of the US economy and the model of US fiscal policy. Among Russian technologies, a special place is occupied by the modelling software systems "SIRENA" and "SIRENA-2" (Institute of economy and industrial engineering of the RAS Siberian branch), the modelling complex "POLIGON-2" (Novosibirsk State University), the "RIM" model (Institute for National Economic Forecasts of RAS), and the "Intersectoral Interactions Model" (Institute of the economy and scientific and technical progress forecasts, USSR Academy of Sciences), the CGE-model "RUSEC," the "Econometric model of the Russian economy," the "CGEmodel of the social and economic system of Russia with integrated neural networks" (Central Economic and Mathematical Institute of
RAS), the "Model of the Region of the Russian North" (Syktyvkar State University), the model "Governor," the "Agent-based model of Moscow" (Central Economic and Mathematical Institute of RAS), etc. [8]. Many complex information and analytical systems, including the information and analytical complex "Prognoz" (CJSC "Prognoz"), are based on the use of simulation models [9].

Despite the advantages of the models presented, the parameters of innovative development of the regions are presented extremely incompletely in them $[10,11]$. At the same time, many models, in particular, those based on econometric equations, do not reflect the adaptive properties of agents of the regional system, all of which causes a decrease in the accuracy of the forecasts obtained.

In this regard, the aim of this study is to develop the concept of a decision support system for the process of formulating strategies for innovative development of regions. To achieve this goal, it is necessary to solve a number of problems, including determining the conceptual framework for the development of DSS and considering the practical aspects of organizing the decision support process.

\section{Conceptual framework and logic of DSS development}

The set of methodological problems in the field of strategic planning of regional development determines the need to develop special management tools that will reflect the key principles of interaction of territorial units in the formation of an innovative economy and will quickly determine the possible consequences of decisions. A qualitative change is required in the methodological and instrumental base of the existing system for managing innovative development of regions through the integration of strategic management methods, economic and statistical analysis, mathematical modeling, decision support theory and simulation modeling. 
In order to achieve this goal, first of all, it is necessary to consider the place of this tool in the regional management system. At the same time, the management of territorial development, in general, includes two components - strategic and operational. The level of strategic management sets priorities for the development of the region; its main parameters define goals for the operational level. The objective of operational management, on the other hand, is to solve current problems aimed at achieving certain particular parameters that characterize the strategic goals of the development of the region. A change in the parameter values of the regional social and economic system (RSES) is directly influenced by regulators (control parameters) and is the result of the activities of the subjects of operational management, as well as processes occurring within the system itself and in the external environment (Figure 1).

As a decision-maker in relation to the task of developing a strategy for innovative develop- ment of the region (indicated in Figure 1 as the "Subject of Strategic Management"), the relevant government bodies should be considered: the composition and structure of the bodies differ slightly in different territorial entities of the Russian Federation. First of all, they include the Ministry of Economic Development and the Ministry of Industry and Innovation Policy.

In the course of solving the tasks of strategic management, the formulation and substantiation of long-term large-scale projects are carried out. Direct generation of a strategy for innovative development of a regional system entails the implementation of a number of stages, including the following:

$\downarrow$ Defining the goals of the strategy. It should be noted that goals should be quantitatively measurable, have clear time characteristics, and be interconnected with more global parameters for the development of the regional economy. Therefore, as indicators characterizing the goals of implementing the innovative strategy for the

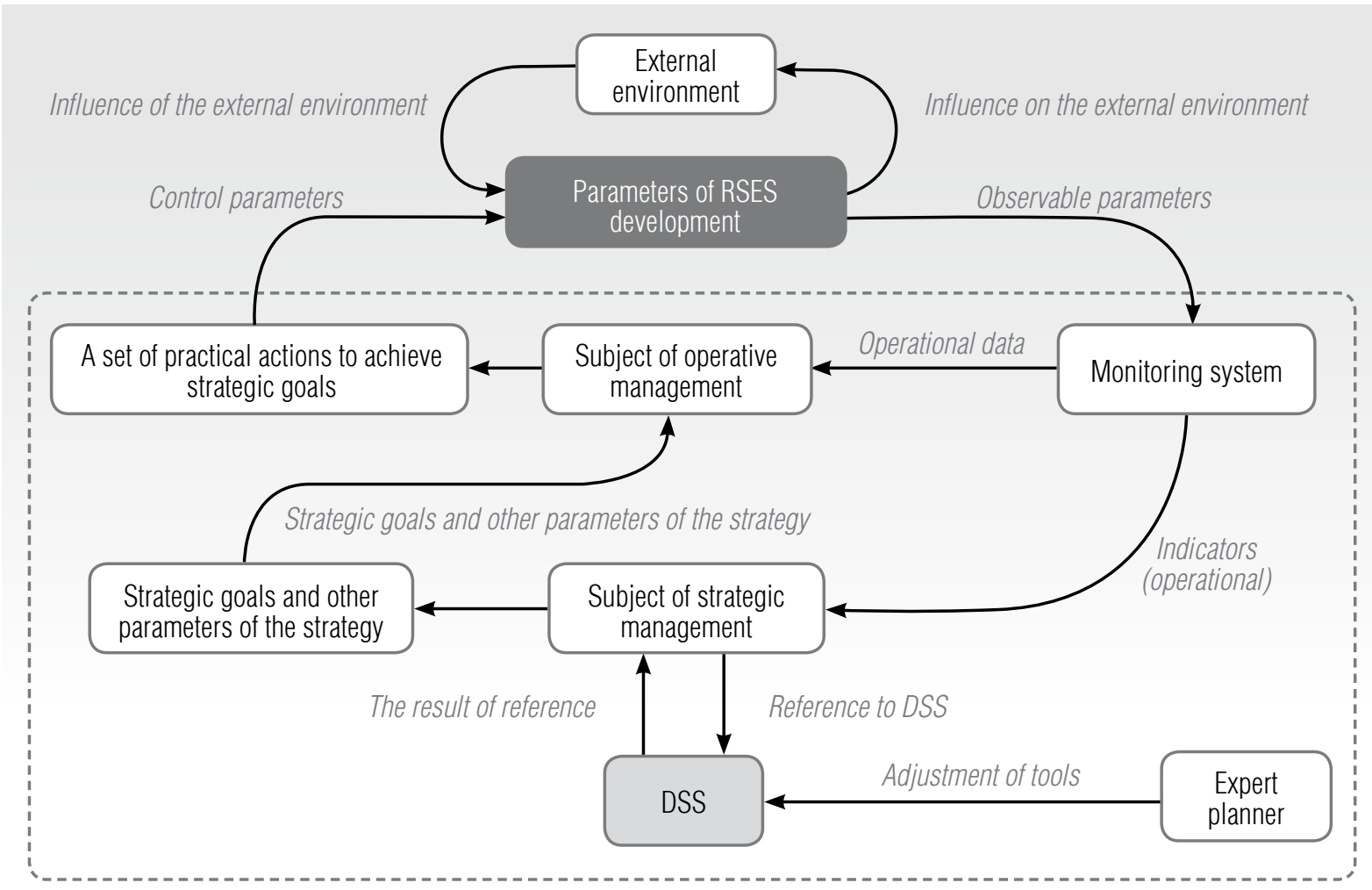

Fig. 1. The place of DSS in the management system for regional development 
development of the region, we can have, for example, the share of innovative products, the region's GRP growth rate and the share of people employed in innovative types of economic activity;

$\downarrow$ Formulation of a list of indicators under consideration. The list of these indicators is determined based on the afore-mentioned goals, the need to consider key factors that influence the innovative activity of economic entities, and the principles of the formation of a regional system model;

Analysis and identification of problems. At this stage, the features of the innovative development of a region, its strengths and weaknesses, and limitations are determined;

- Analysis of the influence of scenario parameters. At this stage, the influence of scenario parameters on the level of innovative activity of economic entities is considered. Within the framework of the proposed approach, modeling the influence of external conditions differs only in the principle of determining the values of indicators, while for the economic agents themselves there is no fundamental difference;

- Identification of controlled parameters and mechanisms for controlling them. It should be noted that in the field of innovative development, management is carried out mainly by indirect methods, in particular, by creating favorable conditions for the formation and implementation of innovations;

- Definition of development goals, a set of targets and their quantitative characteristics. At this stage, using the methods of economic and mathematical modeling, the planned values of the previously considered indicators are substantiated;

$\downarrow$ Formulation of a set of measures aimed at achieving the goal. The use of DSS at this stage provides the opportunity to take into account previously obtained results of state policy to enhance the innovative potential of a region. For these purposes, an appropriate precedent base may be applied; $\downarrow$ Substantiation of the efficiency of measures and assessment of the amount of necessary resources.

From the list presented, it follows that the task of substantiating the parameters of innovative development of the region is multi-faceted and must reflect the behavior of agents of the regional system. This statement of the problem determines the need for the synthesis of various approaches to research. A similar requirement is implemented when using DSS based on adaptive-simulation models (ASM) [12].

Within the framework of this study, the region's ASM is understood as a model based on the idea of consistent adaptation to change in the economic situation of not only the goals and behavior of individual agents (and, accordingly, their strategies), but also the management subsystem. It should be noted that the complex social and economic systems modeled in this case are also adaptive, which leads to the use of the ASM of the region to develop a strategy for its development.

In general, the theoretical substantiation for the development of such a problem-oriented decision support system should include the implementation of several successively interconnected stages that determine the main design features.

Within the framework of the conceptual stage, one must clearly define the basic principles and requirements for the development of decision support tools applicable to developing strategies for innovative development of regions.

The key principle of this study is a systematic approach, consisting in the need to analyze all the basic elements and interconnections of the regional system that form the basis for innovative development, as well as a description of their most significant properties and the determining factors for innovative development. At the same time, such principles as adaptability and consistency of decision-making procedures by agents and the regional management system in the framework of the implementation 
of measures of state social and economic policy are also significant. The principle of integrity requires consideration of various aspects that determine the degree to which the innovative potential of a region is implemented, including economic, social, institutional, organizational, technical and other factors. The principle of conformity with the objectives of the study predetermines limitations on the structure of the parameters under consideration and helps to avoid significant deviations associated with the diversity of life in society, including by focusing on the factors of innovative development of the region. The principles of scientific validity and practical applicability, complementing each other, provide orientation, on the one hand, on a scientific basis (including the previously mentioned technologies in the field of formulating, implementing and disseminating innovations), and on the other hand, on the tasks of economic development facing public authorities of the territorial entities of the Russian Federation. Another important principle is the comparability of data, due, inter alia, to the need to use heterogeneous and different-sized characteristics obtained from various sources and relating to different time periods.

It is also necessary to formulate a common research methodology, substantiate approaches, methods and technologies, as well as determine the concept of reflecting adaptive management schemes in the simulation model of the region's economic system (for example, using evolutionary procedures as part of decision support [13]). It should be noted that the research methodology reflects a systematic view of the region with the determination of the place, role and relationships of economic, social and innovative processes in the reproduction process, formalized on the basis of the adaptive-simulation model (ASM) of the region.

In the future, during the design and mathematical formalization of the simulation model, we see the integration of structural elements and functional relationships which are nec- essary to substantiate the parameters of the region's innovative development strategies. In this regard, on the basis of the methodology presented, one must develop logical, informational and mathematical models for the entire complex of economic agents under consideration. At the same time, it is necessary to develop a management subsystem designed to solve the problem of innovative development.

This subsystem, in our opinion, includes an indicative planning model and a set of control parameters that can be used to substantiate the parameters of economic development strategies by utilizing the innovative potential of the region. In addition, the development of an algorithm for classifying situations based on fuzzy logic methods [14, 15] and adjusting the indicative plan will make it possible to determine the necessary regulatory effects. This procedure is carried out to achieve the planned guidelines for the development of a region as part of adapting the functioning strategy of both the economic subsystem and the management subsystem.

Among the factors of innovative development, researchers distinguish the following:

$\checkmark$ strategic (the quality of strategic planning, the level of formation of the national innovation system);

$\downarrow$ economic (the availability of financial resources of organizations, the investment situation, the variety of forms of management);

$\downarrow$ organizational and management (the level of training in the field of innovation management, the availability of scientific and research and technology potential, the level of development of innovative infrastructure);

- technical and technological (deterioration of fixed assets, complexity and features of production, development and implementation of innovations in economically strong businesses);

$\downarrow$ social (the prestige of various types of labor activity, the lack of highly qualified specialists); 
- institutional (the state of the regulatory framework, the level of state support, financing of scientific and technical programs);

$\checkmark$ market (demand for an innovative product, the level of development of market infrastructure).

Turning to the direct development of DSS software, it is necessary to systematically integrate the above models and algorithms into a single tool. In particular, we are talking about databases on the state of economic agents and the external environment, the user interface, the control module, the system for outputting the results, etc. This approach is generally consistent with research by Russian and foreign authors [16]. It also requires the development of methodological support for the use of DSS when substantiating the parameters of the strategy for innovative development of a region. These methods should contain a description of the process of developing an indicative plan, determining the parameters of the regulatory impact, as well as conducting computational experiments.

Within the framework of the practical testing of the proposed tools, there are plans to implement a set of scenario experiments using the ASM of a region to substantiate the most appropriate strategy for innovative development in the mid-term.

The decision support tools thus developed differ from the information and analytical systems used today in that they use ASM, which is focused on substantiating the parameters of the strategy for innovative development of the economy. This class of models makes it possible to holistically reflect adaptive properties in the behavior of agents and the reaction of the control subsystem as part of the implementation of strategies. The proposed model is distinguished by the presence of integrated circuits of interaction of subjects in various situations, which provides the opportunity to adapt their resource strategies in the process of determining agreed development goals.

\section{Practical aspects of the organization of decision support using the adaptive-simulation model}

From a practical standpoint, the set of tasks to be solved with the use of the decision support tools we developed is determined based on the sequence of stages in the development of a strategy for innovative development of a region and the need to take into account the advantages and disadvantages of individual approaches [17]. In this regard the following are among the basic tasks:

^ collection and storage of factual information, including structured (in the form of decision-making rules) and weekly structured information (in the form of ontologies and precedent bases);

$\checkmark$ assessment of observed and predicted situations using a problem-oriented knowledge base with a logical inference mechanism;

$\downarrow$ making a forecast of changes of the situation in certain conditions on the basis of an adaptive-simulation model;

$\checkmark$ substantiation of a set of recommendations for the development and adjustment of key parameters to manage the region's innovative development.

Taking into account the features of the functioning and development of the control object, as well as taking into account the goals and objectives of the development of tools, it is advisable to use a simulation model reflecting the adaptive properties of the behavior of economic agents as its core. At the same time, the characteristics of the agent in question and decision-making rules based on both their own experience and the analysis of the behavior of other agents are important. The solution to these problems is ensured by using the capabilities of the ASM of the region, which integrates three key levels within the framework of a single design - economic agents, government, and the macro-environment. 
Of the entire set of parameters describing the external environment of the agent (including the characteristics of contractors), only a limited part of them is perceived by the economic agent. In addition, information on the state of the agent is also available to him only partially. Based on this, decisions are made by the agent on the basis of limited knowledge (Figure 2). Based on this information, as well as taking into account the existing rule bases and knowledge base, the agent classifies situations and makes decisions. Simultaneously with the decision itself, the agent forms an image of the desired result of the implementation of the strategy. Moreover, the decision within the framework of this study also means the possible refusal of the agent to take any actions. The implementation of the decision and, therefore, the consequences of this decision are influenced by the parameters of the external environment, including the active reaction from the contractors. Thus, the consequences of the decision to one degree or another differ from the expected results. In

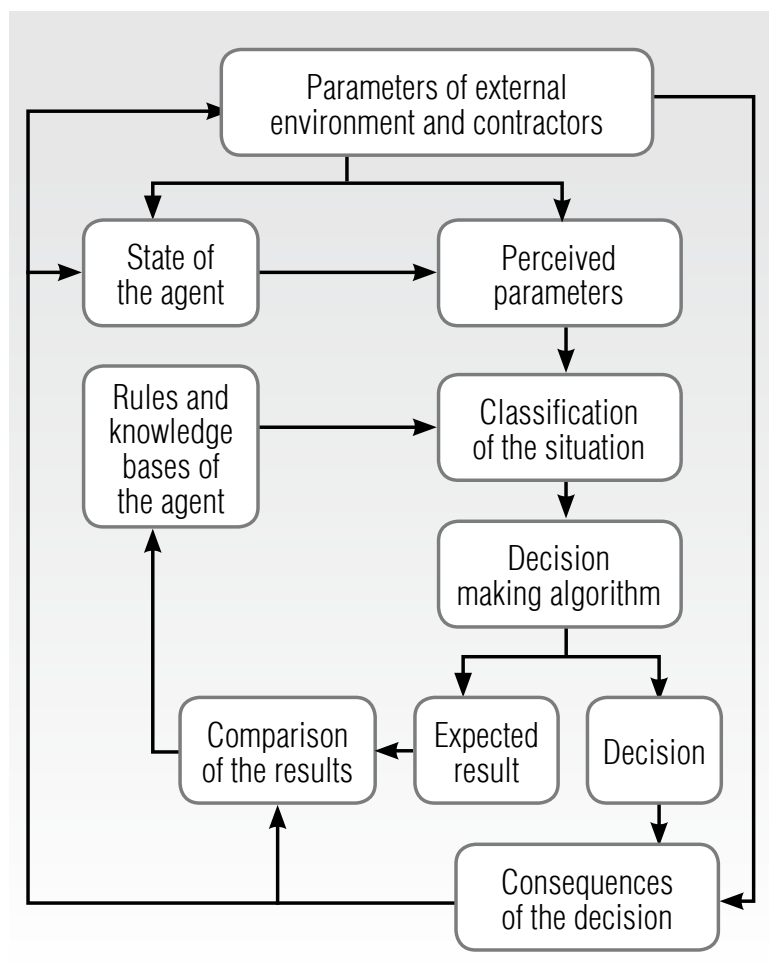

Fig. 2. Aggregate scheme of agent's performance the course of comparison by the agent of the expected and obtained results, either the rules and knowledge of the agent are confirmed (if the results coincide), or a correction of its rules and knowledge bases takes place.

Moreover, in subsequent cycles of the situation analysis and decision-making, the agent in question is guided by a new set of rules and knowledge. In accordance with this algorithm, the agent is being trained and adapted. That is, having a "memory," he is able not only to adjust the quantitative parameters of the decision, but also to supplement the existing rule base in order to identify qualitatively new situations and develop appropriate decisions.

Another way of adjusting the rule base and agent knowledge base is the "exchange" of rules and knowledge with contractors. Such a mechanism does not imply a direct comparison of the expected and observed results obtained during decision-making. Through this process, the most important properties of agents in the social and economic system are implemented, mainly: adaptability and learning ability. The reflection of these properties allows us to model regional processes not from the position of a mechanistic approach, but reflecting the behavioral characteristics of various agents.

Within the framework of the proposed model, it seems appropriate to consider agents of three types - "Population", "Enterprises" and "State and municipal government bodies." In an aggregated form, the logical model of the regional system is presented in Figure 3. At the same time, the formation of an agentbased model implies the availability of many parameters characterizing each agent of the model belonging to one or another type. So, for the agent "Population," not only indicators such as "Sex" and "Age" can be considered, but also "Level of Education," "Tendency to saving," etc. Focusing on the innovative component of the economic development of the region, it should be noted that each of the agents of the "Enterprise" type has such char- 
acteristics as "Identifier of economic activity," "Volume of shipped products," "Profitability of production," etc., each of which anyhow affects the share of innovative products. Similar studies confirm the numerosity of factors that influence the level of innovative development of the region In particular, [18] demographic, economic, financial, labor, social, investment and some other factors were singled out in the research, the total number of which is 119 units.

The management of innovative development within the framework of the proposed model is an adjustment of the parameters that influence the behavior of agents of the regional system. The most important parameters in this case are the following:

$\downarrow$ GRP of the region;

$\downarrow$ the amount of budget expenses in the field of "National Economy;"

$\downarrow$ level of average monthly accrued wages in the region;

$\downarrow$ rates of growth of the amount of investments in fixed assets;

$\downarrow$ deterioration level of fixed assets;

$\downarrow$ the number of post-graduate students and doctoral students;

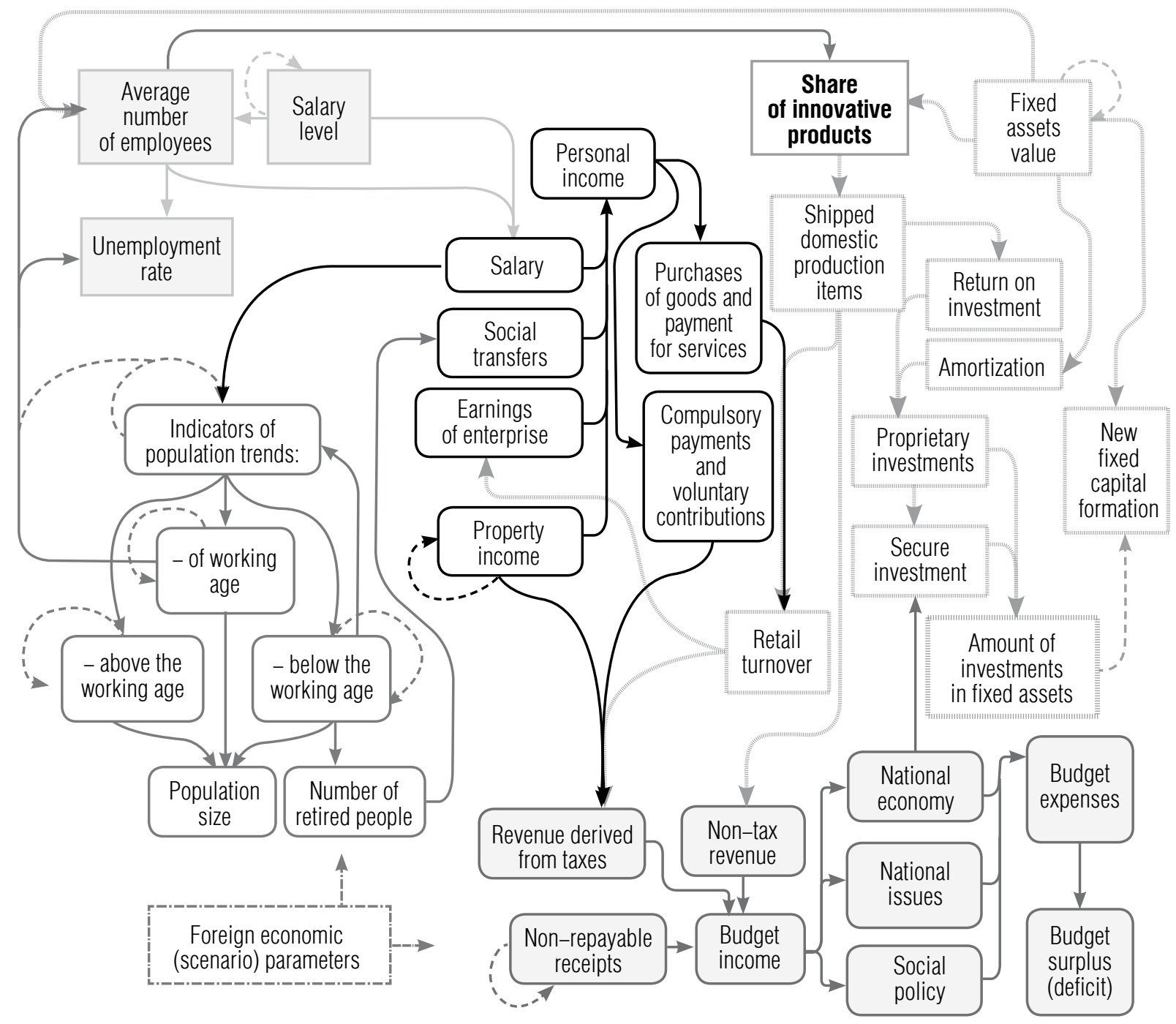

Fig. 3. Aggregated logical structure of a region model 
$\downarrow$ rates of taxes and fees, the value of which can be adjusted at the level of territorial units of the Russian Federation.

In addition to quantitative indicators, it is also necessary to take into account qualitative parameters, such as the quality of strategic planning and the level of formation of the national innovation system. It is suggested that these parameters be evaluated by an expert method and further used in calculations using fuzzy logic methods. The state of these parameters in the aggregate determines the class of the situation, which determines the degree of involvement of the innovative potential of the region. Another feature of the management of innovative development of a region taken into account within the framework of the model is the kind of spread of innovation. Thus, the interaction of an agent with innovatively active contractors increases its own level of innovative activity. The factor of diffusion of innovations is thereby taken into account. The question of taking into account such a factor as the demand for innovation(s) remains open. These parameters determine the specifics of the model for the considered task of managing the innovative development of a region.

Within the framework of the proposed model, the functioning of the agent is defined by a set of conditions and relevant rules of behavior. Adjustment of conditions can lead to both quantitative and qualitative changes in the characteristics of the agent. Such a structure of ASM formulation makes it possible to obtain balanced forecast estimates of regional development indicators. At the same time, the economic and mathematical model alone does not allow us to solve all the tasks assigned to the decision support system, and it needs to be supplemented with a complex of functional units. The composition and interrelation of the units is determined on the basis of the tasks defined for this tool (Figure 4).

Making decisions requires an appropriate reference database. For its formation within the framework of the proposed DSS, a data entry and adjustment unit is provided. Moreover, the features of the existing approach to assessing the innovative development of the region are such that subsequent adjustments to the applied methodological base are very likely. Therefore, one must provide for the possibility of changing the number and structure of indicators, as well as the adjustment of previously entered data.

Given the need for periodic updating of data, an objective condition for the effective operation of the tools is the arrangement of monitoring of ongoing processes according to strictly established parameters. This allows you to form a statistical base for solving managerial problems and track the consequences of decisions, that is, to improve the rule base and precedent base used. Today working with large amounts of information is impossible without using modern information technologies for data mining and processing. It seems appropriate to organize data storage based on the concepts of OLAP and Data Mining. Specialists in this field indicate that by using these technologies it is possible to identify hidden patterns in large amounts of information [19, 20].

In addition, the data entry and adjustment unit is used to set the task by the decision maker (DM). In Figure 4, the indicated problem is solved within the framework of the task formulation unit. The feasibility of including this unit is determined by the variety of practical tasks and areas of application of the tools developed, as well as the need to enter data characterizing the choice of a regional development strategy.

The strategy formulation unit ensures determination of a unified strategy for the development of a region and allows for the pre-adjustment of a number of model parameters in order to determine the priority direction of development. In particular, investment-oriented, socially-oriented, innovative [21], integrated and other strategies can be considered. Based on the foregoing, the data entry unit acts as a user interface for entering statistical information, scenario and control parameters.

The task of determining the parameters of innovative development of the regional system 


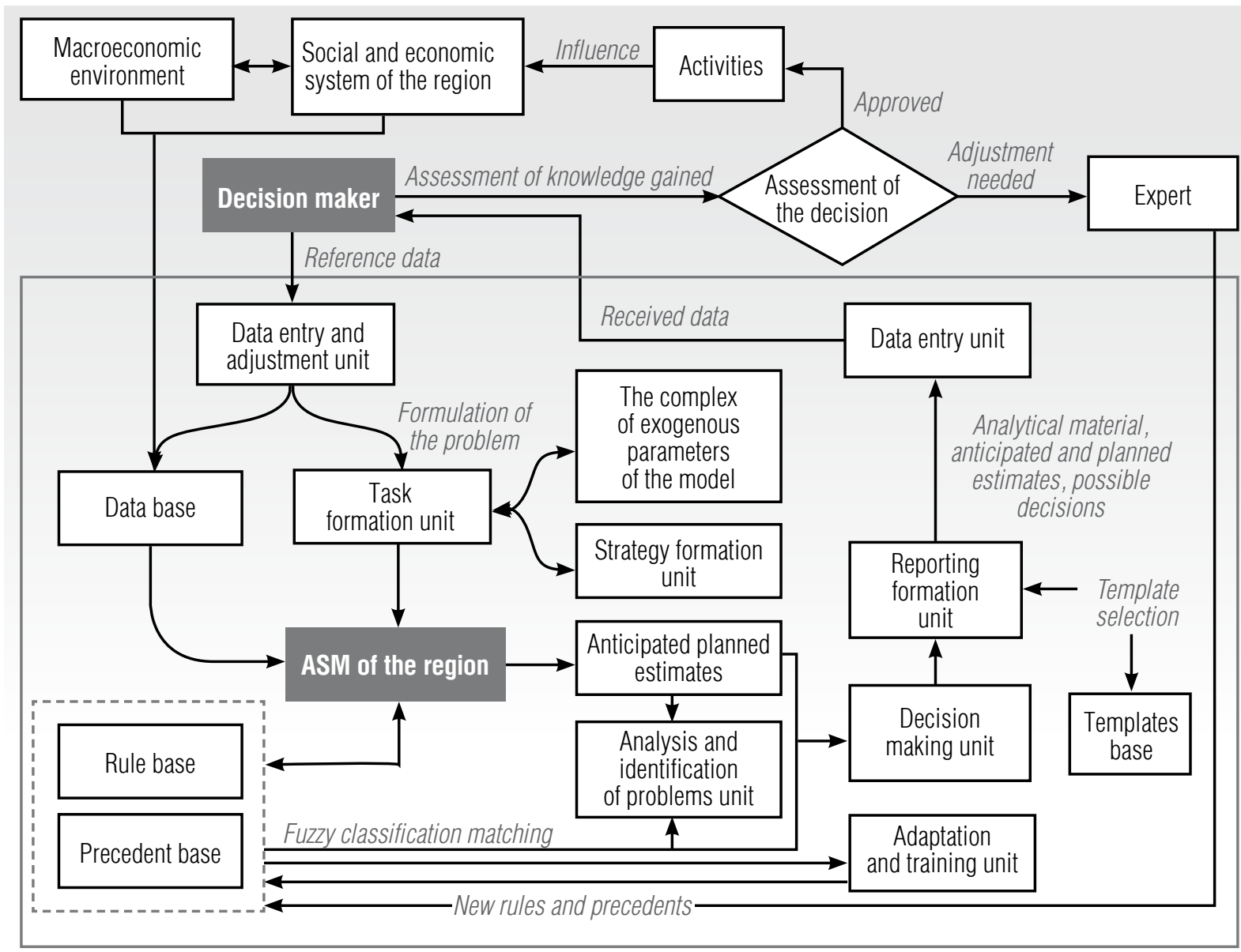

Fig. 4. DSS organization scheme based on the ASM of the region

(including the issues of information support for the procedures for developing a strategy for innovative development of the region [22]) imposes some limitations on model experiments. Thus, it seems necessary to determine the level of innovative development of the territory [23]. Specialists in this area note that within the framework of solving this problem, the following restrictions can be additionally established [24]:

aggregation of a set of criteria of different sizes and multidirectional in their dynamics;

consideration of the significance of the criteria within the framework of formulating the integrated development indicators;

formalization of fuzzy characteristics for effective analysis of qualitative information, as well as clear quantitative data; $\checkmark$ linking the integral indicator with the target priorities for the strategic development of a region.

The simulation results so obtained serve the analysis and identification of problems unit. At this stage, a structural analysis, analysis of dynamics and other types of analysis are carried out aimed at the direct identification of the problem and the factors of its occurrence. To solve this problem, the precedent base [25] is used; it stores information about the possibility of using the accumulated experience to solve new problems. The enlarged precedent structure includes two elements - the identification and the teaching parts. On the basis of anticipated and planned estimates that were determined during the analysis of development problems, and a set of precedents, DSS forms a set 
of decisions for further assessment according to certain criteria.

One of the key components of the decision support system is the decision-making unit. Within the framework of this unit, it is suggested to implement a procedure for classifying situations and comparing them with known precedents to determine further actions. To solve this problem, methods from the theory of fuzzy logic can be used. This approach allows us to track gradual changes in the properties of agents of the regional system, as well as to consider not only quantitative, but also qualitative characteristics. The most significant step is the formulation of fuzzy set adjectives that describe the semantics of the basic values of fuzzy and linguistic variables. The heterogeneity of information sources should be taken into account. Moreover, the choice of decisions should reflect the specifics of innovative development.

The final stage is the formation of a report on the results of simulation experiments and the proposed directions for solving the problems identified. At the same time, it is advisable to use standard reports that allow decision makers to more quickly familiarize themselves with the received data. It should be taken into account that the decision support system is only a tool that allows you to prepare a decision, and it should not replace the decision-maker, who has full responsibility [26]. Based on this, an assessment of the knowledge gained is carried out. When coordinating the proposed decision on the basis of its key parameters, a set of measures is being developed, the implementation of which leads to an adjustment of the parameters of the regional system. If the proposed decision has not been agreed upon, then the rule bases and precedents bases are adjusted with the involvement of relevant experts, and the DSS is restarted.

In addition to these functional units and ASM, to use the decision support system requires appropriate methodological support associated with the practical use of tools. It should include the following methodologies:

$\checkmark$ a methodology for collecting and processing information about the state of the region, economic agents and the environment;

$\checkmark$ the methodology to set an experiment with ASM of the regional system;

$\checkmark$ methodology for the development of managerial decisions based on DSS.

The proposed decision support system can become a universal tool that provides decision makers with important information for decision making on the retrospective, current and future conditions of the regional system, allowing one to analyze and identify possible decisions to existing problems.

\section{Conclusion}

In course of the study, a conceptual scheme for a decision support system in the field of managing a region's innovative development was developed. The place of the adaptive simulation model was justified. We identified the possibilities of its application within the framework of developing forecasts and plans for the development of the region and in assessing the effectiveness of the implementation of public policy measures. A procedure for decisionmaking and a set of functional units providing the final user's work with the ASM of the region are proposed.

The theoretical significance of the study is to expand the possibilities of complex use for solving the problems of strategic development of regional social and economic systems, both methods of management theory and decision support and intellectual information technologies, as well as economic and mathematical methods and modern technologies of simulation modeling. We should also note that the software tool is practice-oriented. The DSS so developed can be used by government bodies in determining the parameters of mid-term development of the regions of Russia, as well as other territorial systems.

\section{Acknowledgments}

This study was supported by the Russian Foundation for Basic Research (RFBR), project No 18-00-00345. 


\section{References}

1. Legris P., Ingham J., Collerette P. (2003) Why do people use information technology? A critical review of the technology acceptance model. Information and Management, vol. 40, no 3, pp. 191-204.

2. Simankov V.S., Vladimirov S.N., Denisenko A.O., Cherkasov A.N. (2008) Methodological aspects of the expert decision-making support systems' construction. Vestnik of Don State Technical University, vol. 8, no 3, pp. 258-267 (in Russian).

3. Palyukh B.V., Kakatunova T.V. (2012) A fuzzy cognitive map as a tool to model innovations at the regional level. Software \& Systems, no 4, pp. 128-131 (in Russian).

4. Zakharova A.A. (2007) Some aspects of the development of information system to support strategic decision-making for innovative development of the region. Modern High Technologies, no 9, pp. 27-29 (in Russian).

5. Akopov A.S. (2010) On one model of adaptive management of complex organizational structures. Audit and Financial Analysis, no 3, pp. 310-317 (in Russian).

6. Antamoshkin A.N., Antamoshkina O.I., Hodos D.V. (2010) Modeling of basic steps of innovative development program formation. Siberian Journal of Science and Technology, no 4, pp. 310-317 (in Russian).

7. Markus M.L., Majchrzak A., Gasser L. (2002) A design theory for systems that support emergent knowledge processes. MIS Quarterly: Management Information Systems, vol. 26, no 3, pp. 179-212.

8. Makarov V.L., Afanasiev A.A., Losev A.A. (2011) Computable simulation model for money circulation in the Russian economy. Economics and the Mathematical Methods, vol. 47, no 1, pp. 3-27 (in Russian).

9. Lychkina N.N. (2007) Simulation models in procedures and systems of strategic decision support at enterprises. Business Informatics, no. 1, pp. 29-35 (in Russian).

10. Burkov V., Burkova I., Irikov V. (2010) Managing regional innovative development: Modern approach. Theoretical and Practical Aspects of Management, no 11, pp. 8-12 (in Russian).

11. Tatarkin A.I. (2016) Innovative vector of the Russian economics: Behavior readiness of the population. Business, Management and Law, no 1, pp. 20-28 (in Russian).

12. Nizamutdinov M.M., Oreshnikov V.V. (2015) A toolkit for forecasting changes in the parameters of regional development on the basis of an adaptive simulation approach. Proceedings of the 3rd International Conference on the Information Technologies for Intelligent Decision Support (ITIDS, 2015), Ufa, 18-21 May 2015, pp. 211-215 (in Russian).

13. Lomazov V.A., Lomazova V.I., Petrosov D.A. (2014) Evolutionary procedure of decision support in modeling of interacting processes. Problems of Contemporary Science and Practice. Vernadsky University, no 2, pp. 82-89 (in Russian).

14. Glushan V.M., Karelin V.P., Kuzmenko O.L. (2009) Fuzzy models and methods of multi-criterion choice in intelligent decision support systems]. Izvestiya SFedU. Engineering Sciences, no 4, pp. 106-113 (in Russian).

15. Nizamutdinov M.M., Oreshnikov V.V. (2016) Formation of the target indicators of regional development strategy using fuzzy logic algorithms. Economics and the Mathematical Methods, vol. 52, no 2, pp. 30-39 (in Russian).

16. Manenti L., Sartori F. (2011) Metadata support to retrieve and revise solutions in case-based reasoning. International Journal of Metadata, Semantics and Ontologies, vol. 6, no 3-4, pp. 185-194.

17. Kravchenko T.K., Seredenko N.N. (2012) The establishment of systems for decision support: integration of the advantages of individual approaches. Artificial Intelligence and Decision Making, no 1, pp. 39-47 (in Russian).

18. Kisurkin A.A. (2012) Factors affecting the innovative development of the region and their classification by management levels. Modern Problems of Science and Education, no 2. Available at: http://science-education.ru/ru/article/view?id=5762 (accessed 20 April 2019) (in Russian).

19. Barabanov I.N., Korgin N.A., Novikov D.A., Chkhartishvili A.G. (2010) Dynamic models of informational control in social networks. Automation and Remote Control, no 11, pp. 172-182 (in Russian). 
20. Nemati H.R., Steiger D.M., Iyer L.S., Herschel R.T. (2002) Knowledge warehouse: An architectural integration of knowledge management, decision support, artificial intelligence and data warehousing. Decision Support Systems, vol. 33, no 2, pp. 143-161.

21. Gazhva V.O., Gubanova E.V. (2016) Innovative development of the Kaluga Region. Proceedings of the International Conference on Directions of Social and Economic Development of Regional Economy, Kaluga, 15 March 2016, pp. 122-125 (in Russian).

22. Tyushnyakov V.N., Zhertovskaya E.V., Yakimenko M.V. (2015) Information and analytical support of situational centers as the basis for developing strategies of a region's innovative development. Fundamental Research, no 11-6, pp. 1253-1257 (in Russian).

23. Gurieva L.K. (2013) New approaches to innovative regions development. Humanities and Social Sciences, no 5, pp. 35-42 (in Russian).

24. Zakharova A.A. (2014) Integrated assessment of innovative development of the region on the basis of fuzzy sets. Scientific Review. Technical Sciences, no 1, pp. 161-168 (in Russian).

25. Eremeev A.P., Varshavskii P.R. (2009) [Modeling of case-based reasoning in intelligent decision support systems. Artificial Intelligence and Decision Making, no 2, pp. 45-47 (in Russian).

26. Kravchenko T.K., Isaev D.V. (2016) Making strategic decisions under risk and uncertainties. Bulletin of the Financial University, vol. 20, no 4, pp. 22-31 (in Russian).

\section{About the authors}

\section{Lilia R. Chernyakhovskaya}

Dr. Sci. (Tech.);

Professor, Department of Technical Cybernetics, Ufa State Aviation Technical University,

12, Karl Marx Street, Ufa 450008, Russia

E-mail: 1rchern@yandex.ru

ORCID: 0000-0002-2447-8864

\section{Marsel M. Nizamutdinov}

Cand. Sci. (Tech.), Associate Professor;

Head of the Sector of Economic and Mathematical Modeling,

Institute of Social and Economic Researches,

Ufa Federal Research Center, Russian Academy of Sciences,

71, Prospekt Oktyabrya, Ufa 450054, Russia

E-mail:marsel_n@mail.ru

ORCID: 0000-0001-5643-1393

\section{Vladimir V. Oreshnikov}

Cand. Sci. (Econ.);

Senior Researcher, Institute of Social and Economic Researches,

Ufa Federal Research Center, Russian Academy of Sciences,

71, Prospekt Oktyabrya, Ufa 450054, Russia

E-mail: VOresh@mail.ru

ORCID: 0000-0001-5779-4946

\section{Alsouy R. Atnabaeva}

Researcher, Institute of Social and Economic Researches,

Ufa Federal Research Center, Russian Academy of Sciences,

71, Prospekt Oktyabrya, Ufa 450054, Russia

E-mail: Alsouy@mail.ru

ORCID: 0000-0002-7042-1180 